\title{
Risk and Exposure of Musculoskeletal Disorders among Dental Surgeons Working in Dhaka City
}

\author{
Dr. Nihar Sultana ${ }^{1 *}$, Prof. Dr. Md. Anower Hussain Mian ${ }^{2}$, Dr. Md.Golam Rubby ${ }^{3}$.
}

\section{AFFILIATION:}

1. Dr. Nihar Sultana

Assistant Professor, Department of Oral Anatomy and Physiology, Mandy Dental College, Dhaka; PhD Research Fellow ( Bangladesh University of Professionals).

2.Prof. Dr. Md. Anower Hussain Mian

Professor and Head, Department of Community Dentistry, Dean, Faculty of Public Health, Bangladesh University of Health Sciences (BUHS). 3.Dr. Md.Golam Rubby

Associate Professor and Head,

Department of Orthodontics, Mandy Dental College, Dhaka.

\section{Article info.}

Received: $29^{\text {th }}$ December, 2018

Accepted: $15^{\text {th }}$ February, 2018

Volume: 9, Issue-1 April, 2019

DOI: https://doi.org/10.3329/updcj.v9i1.41199

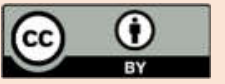

(c) Authors retain copyright and grant the journal right of first publication with the work simultaneously licensed under Creative Commons Attribution License CC - BY 4.0 that allows others to share the work with an acknowledgment of the work's authorship and initial publication in this journal.

https://creativecommons.org/licenses/by/4.0/

Publisher: Update Dental College, Dhaka, Bangladesh

Web: www.updatedentalcollege.edu.bd

E-mail: updcj@hotmail.com

* Corresponding Author Dr. Nihar Sultana Assistant Professor Department of Oral Anatomy and Physiology Mandy Dental College \& Hospital, PhD Research Fellow (BUP) Phone: 01712-843965 E-mail: nihard40@gmail.com

\section{Citation}

Dr. Nihar Sultana, Prof. Dr. Md. Anower Hussain Mian, Dr. Md.Golam Rubby . Risk and Exposure of Musculoskeletal Disorders among Dental Surgeons Working in Dhaka City. Update Dental College Journal. 2019 April; 9(1): 3-7 DOI: https://doi.org/10.3329/updcj.v9i1.41199

\begin{abstract}
Background: Musculoskeletal disorders (MSDs) are the most important occupational health problems particularly in dental professionals. Dentists are among the workers who are more often susceptible to this disorder, as because their work includes risk factors that may lead to this disorder. The study aims to determine the prevalence of MSDs among dental surgeons, also the risk and exposure of this disorder by assessing job postures and the correlation between them.
\end{abstract}

Methods : This cross sectional study was conducted among purposively selected 86 dental surgeons working in eight different tertiary level public and private hospitals in Dhaka city. A structured questionnaire was used for data collection, where Nordic Musculoskeletal Questionnaire(NMQ) used which records the prevalence of MSDs in terms of musculoskeletal symptoms and to assess the risk and exposure of MSDs, Rapid Entire Body Assessment (REBA) score sheet, Quick Exposure Check (QEC) have been used respectively by $10-$ 15 minutes observing each study subject during different dental operating procedures. After data collection analysis of data was performed by using SPSS software (Version 22).

Results : More than $63 \%$ and $47 \%$ of the participants reported pain and discomfort in at least one body region in the last 12 months and the last 7 days respectively. The major affected part was neck, followed by lower back, shoulders and hands / wrists. In different field of specialization among the study subjects musculoskeletal symptoms were highest in oral and maxillofacial surgeons followed by general practitioners, orthodontists, endodontists, prosthodontists. The exposure assessment (QEC) showed that a small percentage $(22.1 \%)$ have acceptable exposure, where $30.2 \%, 47.7 \%$ had medium exposure and high exposure respectively. Whereas the risk assessment (REBA) showed that $59.3 \%$ of the participants were in medium risk group that necessitates further investigation and needs to implement change. Pearson's correlation test indicated that there is a strong positive correlation between the current exposure and the risk $(r=0.832)$ and the relationship between exposure and risk of MSDs was found to be highly significant as $p<$ 0.01 . Highly significant association found between risk level according to REBA score and the exposure level according to QEC score with MSDs ( as $p$ value < $.01)$.

Conclusion: This study concludes that high prevalence of MSDs and high risk levels as well as exposure levels according to REBA and QEC, suggest inappropriate and incorrect ergonomic postural habits existing among the dental surgeons which necessitates further investigation and attention on this issue to combat with this disorder among dental professionals.

\section{Key words:}

Musculoskeletal disorders; Dentists; Risk; Exposure, Occupational health.

\section{Introduction}

Musculoskeletal disorders (MSDs) is prevalent world over and is one of the commonest causes of long-term pain and disability affecting hundreds of millions of people. This fact has been recognized by World Health Organization (WHO) and United Nations with their endorsement of the Bone and Joint decade $2000-2010{ }^{[1]}$ This disorder is characterized by 
presence of discomfort, disability or persistent pain in the joints, muscles, tendons, and other soft parts, caused or aggravated by repeated movements and prolonged awkward or forced body postures. ${ }^{[2]}$ MSDs are some of the most important work-related problems currently reported. Dentists are among the workers who are more often susceptible to this disorder ; their work includes risk factors that may lead to many pathologies such as tendinitis, synovitis, tenosynovitis, and bursitis. ${ }^{[3]}$ About two out of three dental professionals experience occupational pain. MSDs account for the most common reason $(29.3 \%)$ for early retirement in dentists worldwide. In our country the prevalence of MSDs in dentistry is not well documented, also the risk and exposure of this disorder among dental practitioners has not uncovered yet by using any standardized tool. By risk and exposure assessment through standardized tools dental surgeons will be able to identify their current risk and exposure level of MSDs, which will be helpful for them to take appropriate measure accordingly. The present study was aimed to determine the prevalence of MSDs among dental surgeons, also the risk and exposure of this disorder by assessing job postures and the correlation between them.

Materials and methods :

This cross sectional study was conducted among purposively selected 86 dental surgeons working in eight different tertiary level public and private hospitals in Dhaka city with the objective to assess the exposure and risk of MSDs among them. Considering each study hospital as a strata data were collected proportionately according to the convenience of both researcher and respondents from those study hospitals. Dental surgeons with minimum 5 years of clinical experience with minimum 20 hours of clinical work per week were included in the study, and those who had history of uncontrolled diabetes, history of any trauma or accident which may influence the musculoskeletal system were excluded from this study. Ethical clearance was obtained from the institutional ethical committee of Bangladesh University of Professionals (BUP) and the reference number is 24.786.51. A pilot study was performed on ten dental practitioners before commencing the study. Prior taking permission from the concerned authority of each study place informing the purpose of the study data were collected from the respondents after taking informed consent by using the interview administered questionnaire including sociodemographic and occupational characteristics. For the analysis of MSDs, Nordic Musculoskeletal Questionnaire (NMQ) was used which records the prevalence of MSDs in terms of musculoskeletal symptoms (ache, pain, discomfort) in the preceding 12 months. ${ }^{[4]}$ It is an internationally accepted instrument to standardize evaluation of MSDs, and consists of questions about nine anatomical regions. Subjects were asked to report whether they had experienced pain or discomfort in any of these nine regions during the previous 12 months or 7 days and whether normal activities were restricted because of these symptoms. To assess the risk and exposure of MSDs,
Rapid Entire Body Assessment (REBA) score sheet, ${ }^{[5]}$ Quick Exposure Check (QEC) ${ }^{\left[{ }^{[6]}\right.}$ have been used respectively by $10-15$ minutes observing each study subject during different dental operating procedures by the researcher. REBA is a postural targeting method for estimating the risks of work related entire body disorders; which gives a rapid, reliable and detailed assessment of the complete body postural risks to any individual who is involved in distinct and repetitive work pattern ${ }^{[7]}$ and the tool QEC assess the exposure to musculoskeletal risk factors of back, shoulders and arms, hands and wrists, and neck before and after an ergonomic intervention. After data collection analysis of data was performed by using SPSS software (Version 22). Both descriptive statistics ( mean, SD, frequency, percentage) and inferential statistics was performed. Test of significance such as Chi-square test was used for comparison and shown with $p$ value, considering the level of significance at $p<0.05$. Pearson's correlation test was applied to understand the current exposure and risk correlation.

Results:

Table 1 : Socio demographic and job related characteristics of dental surgeons

\begin{tabular}{|c|c|c|c|}
\hline \multirow{10}{*}{$\begin{array}{c}\text { Socio } \\
\text { demographic } \\
\text { variables }\end{array}$} & \multirow{3}{*}{ Sex } & Category & n (\%) \\
\hline & & Male & 53 (61.6) \\
\hline & & Female & $33(38.4)$ \\
\hline & \multirow{3}{*}{ Marital status } & Married & $76(88.4)$ \\
\hline & & Unmarried & $9(10.5)$ \\
\hline & & Divorced & $1(1.2)$ \\
\hline & \multirow[t]{2}{*}{ Religion } & Islam & $79(91.9)$ \\
\hline & & Hindu & $7(8.1)$ \\
\hline & Age (in years) & \multicolumn{2}{|c|}{$\begin{array}{c}\text { Mean }( \pm \text { SD) }: 35.7( \pm 5.7) \text { years } \\
\text { Range }: 28-62 \text { years }\end{array}$} \\
\hline & $\begin{array}{l}\text { Body mass } \\
\text { index (BMI) }\end{array}$ & \multicolumn{2}{|c|}{$\begin{array}{c}\text { Mean }( \pm \text { SD) : } 24.05( \pm 3.238) \\
\text { Range : } 17.61-33.19\end{array}$} \\
\hline \multirow{3}{*}{$\begin{array}{l}\text { Job related } \\
\text { variables }\end{array}$} & $\begin{array}{l}\text { Practicing } \\
\text { hours (per } \\
\text { week) }\end{array}$ & \multicolumn{2}{|c|}{$\begin{array}{c}\text { Mean }( \pm \text { SD) }: 46.5 \pm 13.5 \text { hours } \\
\text { Range }: 21-96 \text { hours }\end{array}$} \\
\hline & $\begin{array}{c}\text { Professional } \\
\text { experience (in } \\
\text { years) }\end{array}$ & \multicolumn{2}{|c|}{$\begin{array}{c}\text { Mean }( \pm \mathrm{SD}): 12.6 \pm 5.1 \text { years, } \\
\text { Range : } 6-32 \text { years }\end{array}$} \\
\hline & $\begin{array}{c}\text { Number of } \\
\text { patients } \\
\text { attended in a } \\
\text { day }\end{array}$ & \multicolumn{2}{|c|}{$\begin{array}{c}\text { Mean }( \pm \mathrm{SD}): 10 \pm 4.9, \text { Range }: 3- \\
30\end{array}$} \\
\hline
\end{tabular}

Above table shows out of $86(100.0 \%)$ dental surgeons $61.6 \%$ were male, $88.4 \%$ were married, almost all $(91.9 \%)$ were Muslim, the mean age of the respondents was $35.7( \pm 5.7)$ years and the mean BMI was $24.05( \pm 3.238)$ with range : $17.61-33.19$. In job related characteristics, the mean practicing hours (per week) was $46.5 \pm 13.5$ hours with range : 21 - 96 hours, $12.6 \pm 5.1$ years was the mean professional experience. 
Figure 1 : Prevalence of musculoskeletal disorders complaint by dental surgeons in the different body regions. [ $n=86]$

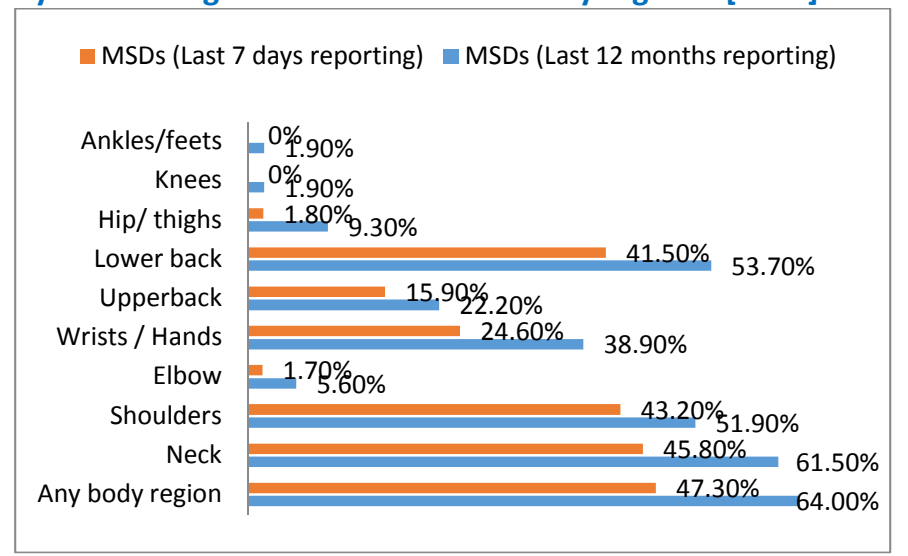

Above figure shows $64.0 \%, 47.3 \%$ dental surgeons complained MSDs in any body region in last 12 months and last 7 days respectively. The highest complained region was in the last 12 months neck (61.5\%), followed by lower back $(53.7 \%)$, shoulders $(51.9 \%)$, hands/ wrists $(38.9 \%)$. The least complained region in the last 12 months was ankles/feet, knees (1.9\%).

Figure 2 : Musculoskeletal disorders in any body region among the dental surgeons with respect to field of specialization.

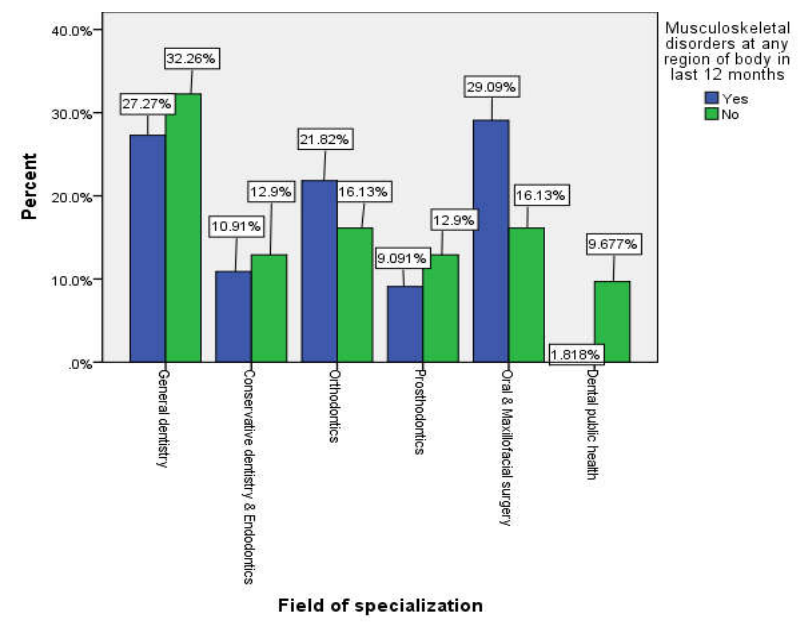

Above figure shows highest percentage (29.0\%) MSDs at any body region observed in the specialization Oral \& Maxillofacial Surgery, followed by $27.2 \%$ in General Dentistry, $21.8 \%$ in Orthodontics, $10.9 \%$ in Conservative dentistry \& Endodontics and $9.0 \%$ in Prosthodontics, only $1.8 \%$ in Dental Public Health. Table 2 : Risk and exposure assessment through REBA and QEC among dental surgeons during different dental operating procedures.

\begin{tabular}{|c|c|c|}
\hline Variable & Category & $\mathrm{n}(\%)$ \\
\hline \multirow{4}{*}{$\begin{array}{l}\text { Risk assessment } \\
\text { (REBA) }\end{array}$} & Low risk & $22(25.6)$ \\
\hline & Medium risk & $51(59.3)$ \\
\hline & High risk & $13(15.1)$ \\
\hline & \multicolumn{2}{|c|}{ Mean $\pm S D: 5.23 \pm 1.88$, Range $: 2-8$} \\
\hline \multirow{4}{*}{$\begin{array}{l}\text { Exposure } \\
\text { assessment } \\
\text { (QEC) }\end{array}$} & Acceptable exposure & $19(22.1)$ \\
\hline & Medium exposure & $26(30.2)$ \\
\hline & High exposure & $41(47.7)$ \\
\hline & \multicolumn{2}{|c|}{ Mean $\pm S D:$ : $79.5 \pm 14.8$, Range $: 48-111$} \\
\hline
\end{tabular}

Above table shows out of 86 (100.0\%) dental surgeons according to REBA score $59.3 \%$ were in medium risk, followed by $25.6 \%$ were in low risk and $15.1 \%$ were in high risk. The mean REBA score was $5.23 \pm 1.88$ with range 2-8. According to QEC score $47.7 \%$ dental surgeons had high exposure followed by $30.2 \%, 22.1 \%$ had medium exposure, acceptable exposure respectively. The mean QEC score was $79.5 \pm 14.8$ with range $48-111$
Table 3 : Relationship between exposure and risk of MSDs among the dental surgeons.

\begin{tabular}{|c|c|c|c|}
\hline \multicolumn{4}{|c|}{ Correlations } \\
\hline & & $\begin{array}{c}\text { Rapid } \\
\text { Entire Body } \\
\text { Assessment } \\
\text { (REBA) } \\
\text { Score }\end{array}$ & $\begin{array}{c}\text { Quick } \\
\text { Exposure } \\
\text { Check } \\
\text { (QEC) } \\
\text { Score }\end{array}$ \\
\hline \multirow{3}{*}{$\begin{array}{l}\text { Rapid Entire Body } \\
\text { Assessment (REBA) } \\
\text { Score }\end{array}$} & $\begin{array}{l}\text { Pearson } \\
\text { Correlation }\end{array}$ & 1 & $.832^{* *}$ \\
\hline & Sig. (2-tailed) & & .000 \\
\hline & $N$ & 86 & 86 \\
\hline \multirow[t]{3}{*}{$\begin{array}{l}\text { Quick Exposure } \\
\text { Check (QEC) Score }\end{array}$} & $\begin{array}{l}\text { Pearson } \\
\text { Correlation }\end{array}$ & $.832^{* *}$ & 1 \\
\hline & Sig. (2-tailed) & .000 & \\
\hline & $\mathrm{N}$ & 86 & 86 \\
\hline
\end{tabular}

Above table shows strong positive correlation between QEC exposure level and REBA risk level among the dental surgeons and the correlation coefficients for final scores of QEC exposure levels and REBA risk levels were 0.832 , which was found to be highly significant as $p$ value $<0.01(r=0.832)$.

Figure 3 : Exposure to risk correlation among the dental surgeons with MSDs at any body region in last 12 months.

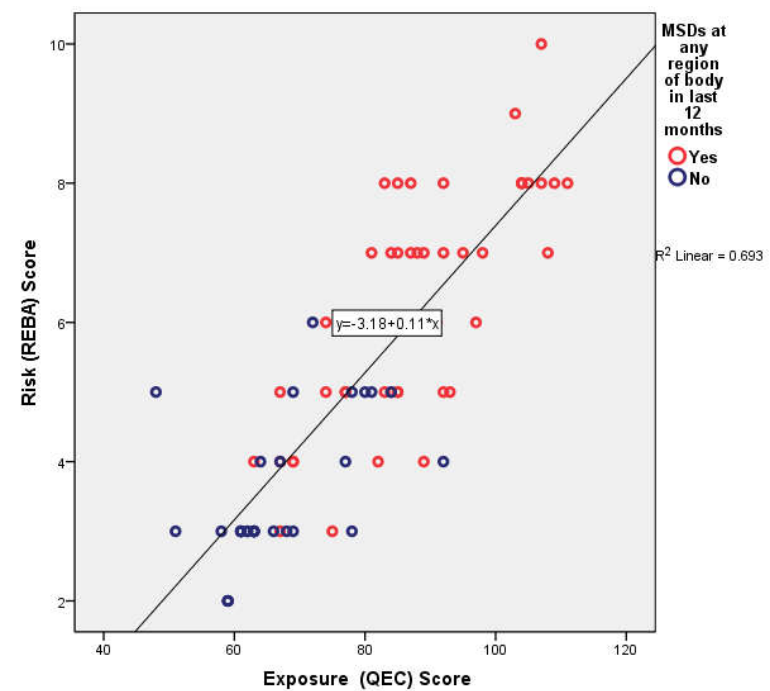

Above figure shows a strong positive correlation between QEC exposure level and REBA risk level with MSDs at any body region in last 12 months.

Website: https://www.banglajol.info/index.php/UpDCJ 
Table 3 :Association between personal and occupational characteristics with MSDs among the dental surgeons

\begin{tabular}{|c|c|c|c|c|}
\hline Variables & Category & $\begin{array}{l}\text { Without } \\
\text { MSDs } \\
\text { n(\%) }\end{array}$ & $\begin{array}{l}\text { With } \\
\text { MSDs } \\
\text { n(\%) }\end{array}$ & $\begin{array}{l}\text { p } \\
\text { value }\end{array}$ \\
\hline \multirow[t]{4}{*}{ Age (in years) } & $\leq 32$ & $12(38.7)$ & $\begin{array}{c}16 \\
(29.1)\end{array}$ & \multirow{4}{*}{$.035^{\mathrm{s}}$} \\
\hline & $33-37$ & $15(48.4)$ & $\begin{array}{c}16 \\
(29.1)\end{array}$ & \\
\hline & $38-42$ & $3(9.7)$ & $\begin{array}{c}17 \\
(30.9)\end{array}$ & \\
\hline & $>42$ & $1(3.2)$ & $6(10.9)$ & \\
\hline \multirow[t]{2}{*}{ Sex } & Male & $16(51.6)$ & $\begin{array}{c}37 \\
(67.3)\end{array}$ & \multirow[t]{2}{*}{$.152^{\mathrm{ns}}$} \\
\hline & Female & $15(48.4)$ & $\begin{array}{c}18 \\
(32.7)\end{array}$ & \\
\hline \multirow[t]{2}{*}{ BMI } & $\begin{array}{c}\text { Underweight \& } \\
\text { normal }\end{array}$ & $16(51.6)$ & $\begin{array}{c}25 \\
(45.5)\end{array}$ & \multirow[t]{2}{*}{$.583^{\mathrm{ns}}$} \\
\hline & $\begin{array}{l}\text { Overweight \& } \\
\text { obese }\end{array}$ & $15(48.4)$ & $\begin{array}{c}30 \\
(54.5)\end{array}$ & \\
\hline \multirow{4}{*}{$\begin{array}{l}\text { Professional } \\
\text { experience (in } \\
\text { years) }\end{array}$} & $\leq 8$ & $7(22.6)$ & $\begin{array}{c}11 \\
(20.0)\end{array}$ & \multirow[t]{4}{*}{$.122^{\mathrm{ns}}$} \\
\hline & $9-13$ & $18(58.1)$ & $\begin{array}{c}20 \\
(36.4)\end{array}$ & \\
\hline & $14-18$ & $5(16.1)$ & $\begin{array}{c}17 \\
(30.9)\end{array}$ & \\
\hline & $>18$ & $1(3.2)$ & $7(12.7)$ & \\
\hline \multirow[t]{2}{*}{$\begin{array}{l}\text { Work status in } \\
\text { last } 12 \text { months }\end{array}$} & $\begin{array}{l}\text { Full time (Both } \\
\text { morning and } \\
\text { evening) }\end{array}$ & $12(38.7)$ & $\begin{array}{c}43 \\
(78.2)\end{array}$ & \multirow[t]{2}{*}{$.000^{\mathrm{hs}}$} \\
\hline & $\begin{array}{l}\text { Part time (Only } \\
\text { morning or } \\
\text { evening) }\end{array}$ & $19(61.3)$ & $\begin{array}{c}12 \\
(21.8)\end{array}$ & \\
\hline
\end{tabular}

s : Significant; ns : Not significant; hs: Highly significant

In Chi -square test statistical significant association found between age and MSDs (as p value <.05) ; also work status in last 12 months had highly significant association with MSDs (as $p$ value <.01). Other socio-demographic and occupational characteristics like sex, BMI, professional experience showed no statistical significant difference between the group with MSDs and without MSDs.

Table 4 : Association between exposure and risk during different dental operating procedures with MSDs among the dental surgeons.

\begin{tabular}{|c|c|c|c|c|c|}
\hline Variables & Category & $\begin{array}{c}\text { Total } \\
(n=86) \%\end{array}$ & $\begin{array}{l}\text { Without } \\
\text { MSDs } \\
\text { n(\%) }\end{array}$ & $\begin{array}{l}\text { With } \\
\text { MSDs } \\
\mathrm{n}(\%)\end{array}$ & $\begin{array}{l}p \\
\text { value }\end{array}$ \\
\hline \multirow{3}{*}{$\begin{array}{c}\text { REBA } \\
\text { (According } \\
\text { to score) }\end{array}$} & Low risk & $22(25.6)$ & $20(64.5)$ & $2(3.6)$ & \multirow{3}{*}{.000} \\
\hline & $\begin{array}{l}\text { Medium } \\
\text { risk }\end{array}$ & $51(59.3)$ & $11(35.5)$ & $\begin{array}{c}40 \\
(72.7)\end{array}$ & \\
\hline & High risk & $13(15.1)$ & $0(0)$ & $\begin{array}{c}13 \\
(23.6)\end{array}$ & \\
\hline \multirow{3}{*}{$\begin{array}{c}\text { QEC } \\
\text { (According } \\
\text { to score) }\end{array}$} & $\begin{array}{c}\text { Acceptable } \\
\text { exposure }\end{array}$ & $19(22.1)$ & $18(58.1)$ & $1(1.8)$ & \multirow{3}{*}{$\begin{array}{l}.000 \\
\text { hs }\end{array}$} \\
\hline & $\begin{array}{l}\text { Medium } \\
\text { exposure }\end{array}$ & $26(30.2)$ & $11(35.5)$ & $\begin{array}{c}15 \\
(27.3)\end{array}$ & \\
\hline & $\begin{array}{c}\text { High } \\
\text { exposure }\end{array}$ & 41 (47.7) & $2(6.5)$ & $\begin{array}{c}39 \\
(70.9) \\
\end{array}$ & \\
\hline
\end{tabular}

hs: Highly significant; MSDs : Musculoskeletal disorders

Above table shows highly significant association between risk level according to REBA score with MSDs among the dental surgeons ( as $p$ value $<.01$ ); and also the exposure level according to QEC score had highly significant association with MSDs ( as $p$ value <.01).
Discussion:

Dental practitioners are highly likely to develop MSDs due to occupational characteristics of repetitive activity. Prevalence of MSDs varies across occupational groups and over national boundaries. This study examined the prevalence and distribution of MSDs as musculoskeletal complaints like pain, stiffness, numbness, fatigue, discomfort with the risk and exposure of this disorder among a cross section dental surgeons population. According to the present study result out of $86(100.0 \%)$ dental surgeons the overall mean age was $35.7( \pm 5.7)$ years with range $28-62$ years, $61.6 \%$ were male, $88.4 \%$ were married, $91.9 \%$ were Muslim, the overall mean BMI was 24.05 ( \pm 3.238$)$ with range 17.61 - 33.13. Regarding job related characteristics it was found that the mean professional experience, the mean practicing hours per week were $12.6( \pm 5.1)$ years, with range $6-32$ years, $46.5( \pm 13.5)$ hours, with range $21-96$ hours respectively and average number of patients attended per day was $10( \pm 4.9)$ with range 3 - 30 patients, which was close to the study findings by Batham et al. ${ }^{[8]}$ The current study result shows that $63.9 \%$, $47.3 \%$ of the participants reported pain and discomfort in at least one body region in the last 12 months and the last 7 days respectively, quite higher prevalence observed in at least one body region in the past 12 months in different studies like $79 \%$ $(n=2166)$ in Gupta et al. ${ }^{[9]}, 83.1 \%(n=213)$ in Saxena et al. ${ }^{[10]}$, $86.8 \%$ in KiHun et al. ${ }^{[11]}, 92 \%$ in Batham et al. ${ }^{[8]}$. In comparison to present study much higher prevalence of MSDs among the dental practitioners in past 12 months observed in different countries study like America (76.0\%) ${ }^{[12]}$, India (78.0\%) ${ }^{[13]}$, Australia (87.2\%) ${ }^{[14]}$, Poland $(92.0 \%)^{[15]}$, Brazil (65.6\%) ${ }^{[16]}$, Saudi Arabia (77.9\%) ${ }^{[17]}$ and in Bangladesh a study by Jahan et al. ${ }^{[18]}$ found that $90.0 \%$ dental practitioners were suffering from musculoskeletal pain during work in last 3 months. The overall prevalence of MSDs in dentistry differs from $63-93 \%$ worldwide. ${ }^{[19]}$ Among all reported MSDs, symptoms were found highest in neck region (61.5\%) followed by lower back (53.7\%), shoulders (51.9\%), hands/ wrists (38.9\%), upper back $(22.2 \%)$ over the past 12 months. Although there were little bit differences in the ranking compared with the previous studies, the regions where the symptoms occurred were similar. The least of complaints in past 12 months were reported at hip/ thigh (9.3\%), elbow (5.6\%), ankles/ feet, knees (1.9\%), which supports the study results of Emmuanuel et al. ${ }^{[20]}$ Present study result found in different field of specialization among the study subjects musculoskeletal symptoms were highest in oral and maxillofacial surgeons followed by general practitioners, orthodontists, endodontists, prosthodontists. In this study the exposure assessment (QEC) showed that a small percentage (22.1\%) have acceptable exposure, where $30.2 \%, 47.7 \%$ had medium exposure and high exposure respectively. Whereas the risk assessment (REBA) showed that 59.3\% of the participants were in medium risk group that necessitates further investigation and needs to implement change, (25.6\%) were in low risk and (15.1\%) of the participants were having high risk, require implementing change. Present study found the mean REBA score was $5.23 \pm 1.88$, which reflects high risk 
level for MSDs that necessitates further investigation and needs to implement change, also the mean QEC score was $79.5 \pm 14.8$, which reflects medium exposure of MSDs that necessitates further investigation. The correlation coefficients for the final scores of QEC exposure levels and REBA risk levels were 0.832 , and the relationship between exposure and risk was found to be highly significant as $p<0.01(r=.832)$, which supports the study results ${ }^{[8,21]}$. In our country no study found using ergonomic postural risk and exposure assessment tools among dental practitioners. On the other hand present study found significant association between age and MSDs, which supports the study results of Cromie et al. ${ }^{[22]}$, but is opposed to the study by Tinubu et al. ${ }^{[23]}$; there were no statistically significant differences in terms of sex, BMI between with MSDs and without MSDs group, which was consistent with the study results ${ }^{[21,24]}$ and inconsistent in case of BMI with the study ${ }^{[8]}$. No statistically significant differences observed in terms of job related characteristics like professional experiences between with MSDs and without MSDs group, which supports the study result of Rafie, et al. ${ }^{[24]}$ but highly significant relationship observed between MSDs and work status in last 12 months $(p=.000)$.

Conclusion : This study concludes that the prevalence of musculoskeletal disorders among dental surgeons is $64.0 \%$ for the past 12 months and $47.3 \%$ for the past 7 days, as reported. High frequency of musculoskeletal complaints and high risk levels as well as exposure levels according to REBA and QEC, suggest inappropriate and incorrect ergonomic postural habits existing among the dental surgeons which necessitates further investigation and attention on this issue to combat with this disorder among dental professionals.

\section{References:}

1. Woolf A D, Pfleger B. "Burden of major musculoskeletal conditions," Bulletin of the World Health Organization. 2003; vol. 81, no. 9, pp. 646-656. PMid:14710506 PMCid:PMC2572542

2. Valachi B, Valachi K. Preventing musculoskeletal disorders in clinical dentistry: Strategies to address the mechanisms leading to musculoskeletal disorders. J Am Dent Assoc.2003;134:1604-12

https://doi.org/10.14219/iada.archive.2003.0048

https://doi.org/10.14219/jada.archive.2003.0106 PMid:14719757

3. Kakosy $T$, Németh L. Musculoskeletal disorders caused by hand-arm vibration. Global Occup Health Network. 2003 ;4 (winter):3-6

4. Kuorinka B, Jonsson A, Kilbom H, Vinterberg F, Biering G, Andersson K, Jorgensen . Standardised Nordic questionnaires for the analysis of musculoskeletal symptoms. Applied Ergonomics. 1987; 18.3, 233-237. https://doi.org/10.1016/0003-6870(87)90010-X

5. Hignett S , McAtamney L. Rapid entire body assessment (REBA). Appl Ergon. 2000; 31(2):201-5, http://dx.doi.org/10. 1016/S0003-6870(99)00039-3

6. David G, Woods V, Li G, Buckle P. The development of the quick exposure check (QEC) for assessing exposure to risk factors for work-related musculoskeletal disorders. Appl Ergon. 2008 ;39:57-69

https://doi.org/10.1016/j.apergo.2007.03.002 PMid:17512492

7. Bhagwat S, Hegde S, Mandke L. Prevalence of Musculoskeletal Disorders among Indian Dentists: A Pilot Survey with Assessment by Rapid Entire Body Assessment. World J Dent . $2015 ; 6(1): 39-44$

https://doi.org/10.5005/jp-journals-10015-1310

8. Batham C, Yasobant S. A risk assessment study on work-related musculoskeletal disorders among dentists in Bhopal, India. Indian J Dent Res. 2016;27:236-41https://doi.org/10.4103/0970-9290.186243 PMid:27411650

7 | P a g e
9. Gupta D, Batra R, Mahajan S, Bhaskar D J, Jain A, Shiju M, et al. Comparative evaluation of the complementary and alternative medicine therapy and conventional therapy use for musculoskeletal disorders management and its association with job satisfaction among dentists of West India. J Tradit Complement Med . $2014 ;$ 4:263-7

https://doi.org/10.4103/2225-4110.126632

PMid:25379469 PMCid:PMC4220505

10. Saxena P, Gupta S K, Jain S, Jain D. Work-related musculoskeletal pain among dentists in Madhya Pradesh, India: Prevalence, associated risk factors, and preventive measures. Asia Pac J Public Health .2014;26:304-9 https://doi.org/10.1177/1010539513497784 PMid:24097923

11. KiHun C, Hwi-young C, Gyeong S H. Risk factors associated with musculoskeletal symptoms in Korean dental practitioners. Journal of Physical Therapy Science . 2016; Jan; 28(1): 56-62. https://doi.org/10.1589/jpts.28.56 PMid:26957728 PMCid:PMC4755974

12. Estrich C. 0390 Musculoskeletal complaints among dental practitioners. Occup Environ Med . 2014; 71: A50

https://doi.org/10.1136/oemed-2014-102362.154

13. Muralidharan D, Fareed N, Shanthi M. "Musculoskeletal Disorders among Dental Practitioners: Does it Affect Practice?" International Journal of Dental Hygiene. 2013; vol. 7, no. 3, pp. 176-181.

14. Leggat PA, Smith DR. Musculoskeletal disorders self-reported by dentists in Queensland, Australia. Aust Dent J. 2006 ; 51: 324-327

https://doi.org/10.1111/j.1834-7819.2006.tb00451.x

15. Kierklo A, Kobus A, Jaworska M, Botuli-ski B. Work-Related Musculoskeletal Disorders among Dentists - A Questionnare Survey. Ann Agric Environ Med . 2011;18:79-84 PMid:21736272

16. Garbin AJI, Garbin CAS, Arcieri RM, Rovida TAS. Musculoskeletal pain and ergonomic aspects of dentistry. Rev. dor. 2015; vol.16 no.2 São Paulo Apr./June.

17. Aljanakh M, Shaikh S, Siddiqui A A, Mansour M A, Hassan S S. Prevalence of musculoskeletal disorders among dentists in the Ha'il Region of Saudi Arabia. Ann Saudi Med. 2015; 35(6): 456-461.DOI: 10.5144/02564947.2015.456 https://doi.org/10.5144/0256-4947.2015.456

18. Jahana K M R, Isratb S, Khan M A A, Chowdhuryd T G, Sharife A R, Quaderf S M A. Muskuloskeletal disorders among dental surgeons at selected private dental hospitals in dhaka city. Updat Dent. Coll .j. 2015;5(1):10-14

19. Ratzon NZ, Yaros T, Mizlik A, Kanner T. Musculoskeletal symptoms among dentists in relation to work posture. Work.2000;15:153-158 PMid:12441484

20. Emmanuel C, Obembe AO, Bamidele S. Work-Related Musculoskeletal Disorders among Health Workers in a Nigerian Teaching Hospital. TAF Prev Med Bull. 2012 ;11:583-8 https://doi.org/10.5455/pmb.1-1320331223

21. Yasobant S, Rajkumar P. Health of the healthcare professionals: A risk assessment study on work-related musculoskeletal disorders in a tertiary hospital, Chennai, India. Int J Med Public Health. 2015 ;5:189-95 https://doi.org/10.4103/2230-8598.153836

22. Cromie JE, Robertson VJ, Best MO. Work-Related Musculoskeletal Disorders in Physical Therapists: Prevalence, Severity, Risks, and Responses. Phys Ther. 2000 ;80:336-51 https://doi.org/10.1093/pti/80.4.336

PMid: 10758519

23. Tinubu BM, Mbada C E, Oyeyemi A L, Fabunmi A A. Work-Related Musculoskeletal Disorders among Nurses in Ibadan, South-west Nigeria: A cross-sectional. BMC Musculoskelet Disord. 2010 ;11:12 https://doi.org/10.1186/1471-2474-11-12

PMid:20089139 PMCid:PMC2823665

24. Rafie F, Jam A Z, Shahravan A, Raoof M, Eskandarizadeh A. Prevalence of Upper Extremity Musculoskeletal Disorders in Dentists: Symptoms and Risk Factors. Journal of Environmental and Public Health. 2015; Article ID 517346, 6 pages. http://dx.doi.org/10.1155/2015/517346 https://doi.org/10.1155/2015/517346 